\title{
Myoinositol to total choline ratio in IDH wild-type gliomas as a prognostic factor on preoperative magnetic resonance spectroscopy
}

\section{Masanobu Kumon}

Department of Neurosurgery, Fujita Health University https://orcid.org/0000-0003-0566-532X

Shunsuke Nakae ( $\square$ snakae.1977@gmail.com )

Kazuhiro Murayama

Fujita Health University

\section{Takema Kato}

Fujita Health University

\section{Shigeo Ohba}

Fujita Health University

Joji Inamasu

Fujita Health University

\section{Masato Abe}

Fujita Health University

\section{Seiji Yamada}

Fujita Health University

\section{Hikaru Sasaki}

Department of Neurosurgery, Keio University

\section{Yoshiharu Ohno}

Fujita Health University

Mitsuhiro Hasegawa

Fujita Health University

Hiroki Kurahashi

Fujita Health University

\section{Yuichi Hirose}

Fujita Health University

\section{Research article}

Keywords: glioma, IDH wild-type, magnetic resonance spectroscopy, myoinositol

Posted Date: June 18th, 2020 
DOl: https://doi.org/10.21203/rs.3.rs-27275/v2

License: (c) (1) This work is licensed under a Creative Commons Attribution 4.0 International License. Read Full License 


\section{Abstract}

Background: Isocitrate dehydrogenase (IDH) wild-type gliomas tend to be pathologically defined as glioblastomas. We previously reported that, unlike IDH-mutant gliomas, IDH wild-type gliomas showed significantly lower ratios of myoinositol to total choline (i.e., the Ins/Cho ratio) on magnetic resonance (MR) spectroscopy. Given that IDH-mutant gliomas also have much better prognoses than IDH wild-type gliomas, we hypothesized that this lower Ins/Cho ratio is associated with malignancy in adults with supratentorial gliomas. Therefore, we calculated the Ins/Cho ratios of patients with supratentorial IDH wild-type gliomas and investigated their progression free survival (PFS) and overall survival (OS) to determine its utility as a prognostic marker.

Methods: We classified IDH wild-type gliomas $(\mathrm{n}=30)$ into two groups based on the Ins/Cho ratios, and compared patient backgrounds, pathological findings, PFS, OS, and copy number aberrations.

Results: Compared with the group with high Ins/Cho ratios, the group with low Ins/Cho ratios had shorter PFS $(P=0.020)$ and OS $(P=0.037)$ durations. Multivariate analysis demonstrated that the Ins/Cho ratio correlated significantly with PFS (hazard ratio $0.34, \mathrm{P}=0.027$ ).

Conclusion: We conclude that the preoperative Ins/Cho ratio can be used as a novel prognostic factor for IDH wild-type gliomas.

\section{Background}

Gliomas, which are diagnosed based on pathological and genetic findings, are among the most common brain tumors [1-4]. Extensive, surgical resection is the preferred initial therapeutic strategy to improve prognosis $[5,6]$; however, such an approach also increases the risk of brain dysfunction because either the border between the tumor and normal brain tissue is unclear or because tumors infiltrate invasively into adjacent healthy brain tissue. Therefore, the ability to predict tumor malignancy preoperatively could help surgeons to plan optimal surgical strategies.

Magnetic resonance (MR) spectroscopy enables us to quantify tumor metabolites noninvasively by analyzing their spectra, and thus, it is widely used for preoperative diagnosis of brain tumors [7]. We previously examined tumor metabolites in adult supratentorial gliomas and reported that the myoinositol to total choline (Ins/Cho) ratios in isocitrate dehydrogenase (IDH) wild-type gliomas were significantly lower than in IDH-mutant gliomas [8]. Given that total choline is thought to represent cell density [9], we presumed that lower ratios indicate myoinositol consumption in a glioma cell. Myoinositols are sugar alcohol in phospholipids of the intracellular membrane [10], and they are produced through food digestion or by hydrolysis or dephosphorylation of the intracellular membrane [10-12]. In astrocytes, myoinositols contribute to adjusting osmotic pressure in response to changes in intracranial pressure [13]. 
Most supratentorial gliomas harboring wild-type IDH are pathologically classified as glioblastomas and tend to have dismal prognoses [1-3]. Molecular factors that contribute to this poor prognosis have been identified based on genetic subtype, including TERT promoter mutations, copy number aberrations (e.g., $+7,10 q$ and 9p21), and epigenetic changes (e.g., histone H3) [14-18]. However, such information is only available after surgical resection, and we ideally need a method for predicting outcomes in patients suspected of having glioblastomas before surgery. Based on the observation that supratentorial gliomas with $I D H$ mutations have better outcomes than those with wild-type $I D H[1,2,3]$, we hypothesized that low Ins/Cho ratios in $I D H$ wild-type gliomas can be used as a prognostic marker for this genetic subtype of glioma.

In the present study, we calculated Ins/Cho ratios by MR spectroscopy for adults with supratentorial IDH wild-type gliomas to investigate the ratio's association with prognosis, its correlation with previously reported prognostic factors, and whether it could be used as a preoperative prognostic factor.

\section{Materials And Methods}

\section{Study design}

We retrospectively investigated 30 cases of newly diagnosed $I D H$ wild-type glioma in patients analyzed by MR spectroscopy between 2013 and 2018 at Fujita Health University hospital. Patients who had already received treatment before MR spectroscopy or who were younger than 20 years old were excluded.

The primary outcomes were the progression free survival (PFS) and the overall survival (OS). PFS was calculated from the date of first operation to the date of confirmed recurrence. OS was calculated from the date of first resection to the date of death. Patient information was last updated in April 2019 for follow-up purposes. All resected tissues were assessed by neuropathologists according to the WHO classification [1].

\section{MR spectroscopy}

A single-voxel ${ }^{1} \mathrm{H}$-MR spectroscopy with point-resolved spectroscopy sequence was performed with a 3 Tesla (T) scanner (Ingenia 3T; Philips Healthcare, Best, The Netherlands) using a dS Head coil and Vantage Titan 3T (Canon Medical Systems Corporation, Otawara, Japan) using a 16 or a 32-channel coil. In each patient, ${ }^{1} \mathrm{H}-\mathrm{MR}$ spectroscopy was performed using the following parameters: repetition time (TR)/echo time (TE), 2000/144 and 35 ms; number of excitation (NEX), 128; bandwidth, $1.61 \mathrm{HZ} /$ point; voxel of interest (VOI) size for metabolic measurements, $15 \times 15 \times 15 \mathrm{~mm}$. T2 weighted images in 3 directions for setting the VOI were determined for each patient by means of the following parameters: repetition time (TR)/echo time (TE), 4250/82 ms; acquisition matrix size, $416 \times 344$; reconstruction matrix, $640 \times 640$; field of view (FOV), $230 \times 230 \mathrm{~mm}$; slice thickness, $4.0 \mathrm{~mm}$; slice gap, $0.8 \mathrm{~mm}$; number of excitation (NEX), 1; reduction factor 1.9. The VOI was selected by a board certified neuroradiologist (K.M) with an experience of 10-15 years' to include the VOls inside the lesion based on T2 weighted 
images in 3 directions. When the tumor contains necrotic and cystic components, these components were included within VOI to accurately evaluate tumor characteristics. In ${ }^{1} \mathrm{H}-\mathrm{MR}$ spectroscopy, myoinositol and total choline were measured with short TE $(T E=35 \mathrm{~ms})$ and long TE $(T E=144 \mathrm{~ms})$ respectively $[19,20$, 21] because of their relaxation time in T2, and mean concentration of MR spectroscopy values were analyzed by automatic quantification program (LCModel; Stephen Provencher, Oakville, Ontario, Canada) [22].

\section{Evaluation of IDHmutation status}

We evaluated $I D H$ mutations using the Sanger method, with codon 132 in $I D H 1$ and codon 172 in IDH 2 analyzed by polymerase chain reaction (PCR). Briefly, DNA was extracted from resected frozen tissue and formalin-fixed and paraffin-embedded tissue (FFPE), using DNeasy blood and tissue kits (QIAGEN, Hulsterweg, Netherland) and an REPLI-g FFPE Kit (QIAGEN).The reaction mixtures for PCR comprised DNA, primers, 10PCR buffer, 10mM dNTP mix (Thermo Fisher Scientific, Waltham, MA, USA), $50 \mathrm{mM}$ MGCL『, and PLATINUM TagDNA polymerase (Thermo Fisher Scientific). After we confirmed the DNA bands of the PCR products in electrophoresis, we added BigDye Sequencing Buffer (Thermo Fisher Scientific), Ready Reaction Mix (Thermo Fisher Scientific), and the same primer to the PCR products, and repeated the PCR. Sequencing was performed with a BigDye Terminator version 3.1 Cycle Sequencing Kit (Thermo Fisher Scientific) and results were analyzed on an ABI 3100 (Applied Biosystems, Waltham, MA, USA).

\section{Next generation sequencing analysis and comparison of Copy number aberration}

We analyzed samples that met our inclusion criteria and classified them by Ins/Cho ratio into high and low and a low ratio groups. We prepared diluted genomic DNA for subsequent experiments. After whole genome amplification using a SurePlex DNA Amplification System (Illumina, San Diego, CA, USA), library preparation was performed with a Nextera XT DNA Library Preparation Kit (Illumina). Sequencing analysis was conducted with a VeriSeq PGS Kit-MiSeq (Illumina), and results were analyzed with BlueFuse Multi Software (Illumina). In all cases, chromosomes were divided into 2500 windows of approximately $1 \mathrm{Mb}$ in size.

\section{Statistical analysis}

We used Fisher's exact test and the MannWhitney Utest to compare age at onset, sex, laterality, MIB-1 index, and pathology between the two groups. PFS and OS were analyzed using the KaplanMeier method and compared with the log-rank test. Cox proportional hazards models were used to determine the relationship between the Ins/Cho ratio and prognosis. Given that most patients were treated with surgery, temozolomide and radiotherapy, and bevacizumab, we selected the following as explanatory factors in the multivariate analysis: gross total resection; subtotal resection, which was defined as $>90 \%$ resection; temozolomide and radiotherapy; bevacizumab; and the Ins/Cho ratio. All statistical analyses were conducted using EZR [23]. 


\section{Results}

\section{Relation of patient and pathology characteristics with the Ins/Cho ratio}

The mean and median values of the Ins/Cho ratios for the 30 patients included in this cohort were 0.75 and 0.67 , respectively. We opted for 0.7 as the cutoff value and classified those patients into high $(\geq 0.7)$ and low $(<0.7)$ Ins/Cho ratio groups ( $n=13$ and 17, respectively). Tables 1 and 2 show the patient characteristics, pathologies, Ins/Cho ratios, and postoperative therapies. Case comprised 25 glioblastoma, two gliosarcomas, three astrocytomas. Two of three astrocytomas gained chromosome 7 and/or loss of chromosome 10q, but the other was not associated with them. There were no statistically significant differences in sex, age at onset, laterality, MIB-1 index, or grade $\otimes$ WHO classification between the two groups. Overall, eight patients underwent reoperation, six patients underwent additional chemotherapy, and seven patients had no treatment after recurrence.

\section{Table 1. Characteristics and treatments of patients}




\begin{tabular}{|c|c|c|c|c|c|c|c|}
\hline Case & Age, sex & Pathology & Recurrence & PFS & Follow-up terms & Outcome & Ins/Cho \\
\hline \multicolumn{8}{|c|}{ First operation / Postoperative therapies / therapies after recurrence } \\
\hline 1 & $42 \mathrm{~F}$ & GBM, Gr $\square$ & Yes & 9 & 22 & Dead & 0.573 \\
\hline \multicolumn{8}{|c|}{$\mathrm{GTR} / \mathrm{TMZ}+\mathrm{RT} / \mathrm{TMZ}+\mathrm{RT}+\mathrm{BEV}+$ other chemotherapies + operation } \\
\hline 2 & $43 \mathrm{M}$ & GBM, Gr $\square$ & Yes & 5 & 12 & Dead & 0.475 \\
\hline \multicolumn{8}{|c|}{$\mathrm{PR} / \mathrm{TMZ}+\mathrm{RT} / \mathrm{BEV}$ + another chemotherapy + operation } \\
\hline 3 & $43 \mathrm{~F}$ & GBM, Gr $\square$ & Yes & 1 & 31 & Dead & 0.507 \\
\hline \multicolumn{8}{|c|}{ GTR / No treatment / TMZ + RT + BEV + other chemotherapies + operations } \\
\hline 4 & $44 \mathrm{M}$ & $\mathrm{GBM}, \mathrm{Gr} \square$ & Yes & 10 & 14 & Dead & 0.167 \\
\hline \multicolumn{8}{|c|}{ GTR / TMZ + RT + BEV / other chemotherapy } \\
\hline 5 & $46 \mathrm{~F}$ & GBM, Gr $\square$ & Yes & 3 & 12 & Dead & 0.450 \\
\hline \multicolumn{8}{|c|}{$\mathrm{GTR} / \mathrm{TMZ}+\mathrm{RT} / \mathrm{TMZ}+\mathrm{RT}+\mathrm{BEV}+$ other chemotherapy } \\
\hline 6 & $62 \mathrm{M}$ & GBM, Gr $\mathrm{c}$ & Yes & 14 & 49 & Dead & 0.516 \\
\hline \multicolumn{8}{|c|}{ Biopsy / TMZ + RT / TMZ + RT + BEV + operation } \\
\hline 7 & $62 \mathrm{M}$ & $\mathrm{GS}, \mathrm{Gr} \square$ & Yes & 26 & 58 & Alive & 1.149 \\
\hline \multicolumn{8}{|c|}{$\mathrm{STR} / \mathrm{TMZ}+\mathrm{RT} / \mathrm{TMZ}+\mathrm{RT}+$ operation } \\
\hline 8 & $63 F$ & GBM, Gr $\square$ & Yes & 17 & 36 & Alive & 1.149 \\
\hline \multicolumn{8}{|c|}{$\mathrm{GTR} / \mathrm{TMZ}+\mathrm{RT} / \mathrm{TMZ}+\mathrm{RT}+\mathrm{BEV}$} \\
\hline 9 & $67 \mathrm{M}$ & $\mathrm{GBM}, \mathrm{Gr} \square$ & Yes & 2 & 2 & Alive & 0.044 \\
\hline \multicolumn{8}{|c|}{$\mathrm{PR} / \mathrm{TMZ}+\mathrm{RT} / \mathrm{BEV}$} \\
\hline 10 & $67 \mathrm{M}$ & $\mathrm{GBM}, \mathrm{Gr} \square$ & Yes & 9 & 10 & Alive & 0.816 \\
\hline \multicolumn{8}{|c|}{$\mathrm{PR} / \mathrm{TMZ}+\mathrm{RT}+\mathrm{BEV} / \mathrm{TMZ}$} \\
\hline 11 & $68 \mathrm{~F}$ & GBM, Gr $\mathrm{c}$ & Yes & 8 & 8 & Dead & 0.227 \\
\hline \multicolumn{8}{|c|}{ GTR / TMZ + RT / No treatment } \\
\hline 12 & $68 \mathrm{M}$ & $\mathrm{GBM}, \mathrm{Gr} \square$ & NO & 6 & 10 & Alive & 1.182 \\
\hline \multicolumn{8}{|c|}{ STR / TMZ + RT / No treatment } \\
\hline 13 & $69 F$ & GBM, Gr $\square$ & Yes & 1 & 12 & Dead & 2.054 \\
\hline \multicolumn{8}{|c|}{ GTR / No treatment / TMZ + RT + BEV } \\
\hline & & & & $7 / 18$ & & & \\
\hline
\end{tabular}




\begin{tabular}{|c|c|c|c|c|c|c|c|}
\hline 14 & $69 \mathrm{~F}$ & GBM, Gr & Yes & 12 & 20 & Dead & 0.655 \\
\hline \multicolumn{8}{|c|}{ GTR / TMZ + RT / BEV } \\
\hline 15 & $70 \mathrm{M}$ & GBM, Gr & NO & 3 & 11 & Dead & 0.854 \\
\hline \multicolumn{8}{|c|}{ GTR / TMZ + RT / No treatment } \\
\hline 16 & $71 \mathrm{M}$ & DA, Gr $\square$ & Yes & 9 & 39 & Dead & 1.702 \\
\hline \multicolumn{8}{|c|}{ Biopsy / TMZ + RT / operation } \\
\hline 17 & $72 \mathrm{M}$ & GBM, Gr $\mathrm{P}$ & Yes & 1 & 22 & Dead & 0.451 \\
\hline \multicolumn{8}{|c|}{$\mathrm{GTR} / \mathrm{TMZ}+\mathrm{RT} / \mathrm{TMZ}+\mathrm{RT}+\mathrm{BEV}$} \\
\hline 18 & $72 \mathrm{~F}$ & $\mathrm{DA}, \mathrm{Gr} \mathrm{c}$ & Yes & 4 & 7 & Alive & 0.952 \\
\hline \multicolumn{8}{|c|}{ PR / No treatment / No treatment } \\
\hline 19 & $73 \mathrm{~F}$ & GBM, Gr & Yes & 1 & 23 & Dead & 0.405 \\
\hline \multicolumn{8}{|c|}{ STR / No treatment / TMZ + RT + BEV + operation } \\
\hline 20 & $74 \mathrm{M}$ & GBM, Gr & Yes & 2 & 20 & Dead & 0.758 \\
\hline \multicolumn{8}{|c|}{$\mathrm{GTR} / \mathrm{TMZ}+\mathrm{RT} / \mathrm{TMZ}+\mathrm{BEV}$} \\
\hline 21 & $74 \mathrm{M}$ & GBM, Gr & Yes & 1 & 20 & Dead & 0.240 \\
\hline \multicolumn{8}{|c|}{ GTR / TMZ + RT / TMZ + BEV + another chemotherapy + Operation } \\
\hline 22 & $74 \mathrm{M}$ & GBM, Gr $\mathrm{P}$ & Yes & 10 & 19 & Alive & 0.893 \\
\hline \multicolumn{8}{|c|}{$\mathrm{STR} / \mathrm{TMZ}+\mathrm{RT}+\mathrm{BEV} / \mathrm{TMZ}+\mathrm{RT}+\mathrm{BEV}$} \\
\hline 23 & $75 \mathrm{~F}$ & GBM, Gr & NO & 6 & 6 & Alive & 0.405 \\
\hline \multicolumn{8}{|c|}{$\mathrm{GTR} / \mathrm{TMZ}+\mathrm{RT}$} \\
\hline 24 & $76 \mathrm{~F}$ & $\mathrm{AA}, \mathrm{Gr}$ & Yes & 1 & 24 & Dead & 0.635 \\
\hline \multicolumn{8}{|c|}{ Biopsy / TMZ + RT / TMZ + BEV } \\
\hline 25 & $77 \mathrm{M}$ & GS, Gr $\square$ & Yes & 13 & 14 & Dead & 0.695 \\
\hline \multicolumn{8}{|c|}{ GTR / TMZ + BEV / No treatment } \\
\hline 26 & $80 \mathrm{~F}$ & GBM, Gr $\square$ & NO & 39 & 39 & Alive & 1.176 \\
\hline \multicolumn{8}{|c|}{$\mathrm{PR} / \mathrm{TMZ}+\mathrm{RT}$} \\
\hline 27 & $81 \mathrm{M}$ & GBM, Gr & Yes & 2 & 3 & Dead & 0.692 \\
\hline \multicolumn{8}{|c|}{ Biopsy / TMZ + BEV / No treatment } \\
\hline 28 & $81 \mathrm{M}$ & GBM, Gr & Yes & 4 & 4 & Alive & 1.397 \\
\hline
\end{tabular}


GTR / No treatment

\begin{tabular}{|c|c|c|c|c|c|c|c|}
\hline 29 & $85 \mathrm{M}$ & GBM, Gr & Yes & 2 & 5 & Alive & 0.279 \\
\hline \multicolumn{8}{|c|}{ Biopsy / TMZ + BEV +RT / TMZ } \\
\hline 30 & $86 \mathrm{~F}$ & GBM, Gr & Yes & 21 & 24 & Dead & 1.111 \\
\hline \multicolumn{8}{|c|}{ STR / TMZ / BEV } \\
\hline
\end{tabular}

Data show the patient and treatment details after the first operation and after recurrence for supratentorial $I D H$ wild-type glioma $(n=30)$. Pathology was diagnosed according to the WHO classification 2016. Abbreviations: AA, anaplastic astrocytoma; BEV, bevacizumab; DA, diffuse astrocytoma; F, female; GBM, glioblastoma; Gr, grade; GS, gliosarcoma; GTR, Gross total resection; Ins/Cho, ratio of myoinositol to total choline; IDH, isocitrate dehydrogenase; M, male; PFS, progression free survival; PR, Partial resection; RT, radiotherapy; STR, Subtotal resection; TMZ, temozolomide.

Table 2. Comparison of patient characteristics by Ins/Cho ratio threshold

Ins/Cho ratio $\geq 0.7 \quad$ Ins/Cho ratio $<0.7 \quad P$ value

\begin{tabular}{cccc} 
& $(\mathrm{n}=13)$ & $(\mathrm{n}=17)$ & \\
\hline Male, $\mathrm{n}$ & 8 & 9 & 0.72 \\
Age at onset, median (years) & 71 & 69 & 0.38 \\
\hline Left side, $\mathrm{n}$ & 8 & 7 & 0.46 \\
\hline MIB-1 index, median & 38 & 46 & 0.41 \\
Grade $\mathrm{C}, \mathrm{n}$ & 11 & 16 & 0.57
\end{tabular}

Abbreviations: Grade $\square$, grade $\mathrm{I}$ in WHO Classification; Ins/Cho, ratio of myoinositol to total choline; n, number of patients.

\section{PFS and OS analysis}

We compared prognosis by the Ins/Cho ratio. During follow-up, tumor recurrence occurred in $94 \%$ of patients with low Ins/Cho ratio (i.e., 16/17) and in 77\% with high Ins/Cho ratio (i.e., 10/13). Moreover, $82 \%(14 / 17)$ of patients with low ratios and 38\% (5/13) with high ratios died. Figures $1 \mathrm{a}$ and $1 \mathrm{~b}$ show that the PFS and OS in those with high ratios were significantly shorter than in those with low ratios, indicating higher recurrence and mortality rates in the patients with low Ins/Cho ratios $(P=0.020$ and 
0.037, respectively). In the multivariate analysis, Cox proportional hazards models revealed that the Ins/Cho ratio was significantly associated with PFS (hazard ratio $0.34, P=0.027$ ), which suggested that the Ins/Cho ratio was useful outcome predictor, especially for PFS. These data are summarized in Tables $3 \mathrm{a}$ and $3 \mathrm{~b}$.

\section{Table 3a. Multivariate analysis of PFS}

\begin{tabular}{ccc} 
Explanatory factor & Hazard ratio (95\% CI) & P value \\
\hline GTR or STR & $0.84(0.36-2.0)$ & 0.68 \\
Use of BEV & $0.76(0.26-2.2)$ & 0.62 \\
\hline Both use of TMZ and RT & $0.52(0.20-1.4)$ & 0.18 \\
\hline Ins /Cho ratio & $0.34(0.13-0.88)$ & 0.027
\end{tabular}

Table 3b. Multivariate analysis of OS

\begin{tabular}{ccc} 
Explanatory factor & Hazard ratio (95\% CI) & P value \\
\hline GTR or STR & $1.6(0.44-5.6)$ & 0.48 \\
Use of BEV & $0.91(0.28-3.0)$ & 0.88 \\
\hline Both use of TMZ and RT & $0.70(0.22-2.2)$ & 0.55 \\
\hline Ins/Cho ratio & $0.33(0.10-1.1)$ & 0.067
\end{tabular}

Tables 3a and 3b show the results of multivariate analysis: we chose GTR or STR, BEV, TMZ and RT, and the Ins/Cho ratio as explanatory factors and analyzed their relevance to PFS and OS. Abbreviations: BEV, bevacizumab; GTR, Gross total resection; Ins/Cho, ratio of myoinositol to total choline; OS, overall survival; PFS, progression free survival; RT, radiotherapy; STR, subtotal resection; TMZ, temozolomide.

\section{Analysis of copy number aberration by next generation sequencing}

We included 20 cases in the next generation sequencing, analyzing nine samples in the group with high Ins/Cho ratios $(\geq 0.7)$ and 11 samples in the group with low Ins/Cho ratios $(<0.7)$. The overall noise value was $<0.3$. Analysis focused on regions where specific genes exist that are associated with poor prognosis in glioblastoma, including 7p11.2 (EGFR), 9p21.3 (p16), 10q23.3 (PTEM [15, 16]. Gain of 7p11.2 was detected in seven cases with high ratios and in six cases with low ratios, loss of 9p21.3 was detected in four cases with high ratios and in three cases with low ratios, and loss of 10q23.3 was detected in four 
cases with high ratios and in three cases with low ratios (Table 4). There were no significant differences between the groups in any other window.

Table 4. Comparison of copy number aberrations by Ins/Cho ratio

\begin{tabular}{cccc} 
& $\begin{array}{c}\text { Ins/Cho ratio } \geq 0.7 \\
(\mathrm{n}=9)\end{array}$ & $\begin{array}{c}\text { Ins /Cho ratio }<0.7 \\
(\mathrm{n}=11)\end{array}$ & P value \\
\hline$+7 \mathrm{p} 11.2$ & $7(78 \%)$ & $6(55 \%)$ & 0.37 \\
$-9 \mathrm{p} 21.3$ & $4(44 \%)$ & $3(27 \%)$ & 0.64 \\
\hline$-10 \mathrm{q} 23.3$ & $4(44 \%)$ & $3(27 \%)$ & 0.64
\end{tabular}

Copy number aberrations identified by next generation sequencing are compared by the Ins/Cho ratio. We defined an effective change of gain or loss when the average value of a window was $>2.5$ or $<1.5$. Abbreviations: Ins/Cho, ratio of myoinositol to total choline.

\section{Discussion}

In this study, we demonstrated that a high Ins/Cho ratio on MR spectroscopy was associated with a better prognosis than a low Ins/Cho ratio according to KaplanMeier curves. The Ins/Cho ratio was significantly associated with PFS by KaplanMeier and multivariate analysis. Of the three cases in which the Ins/Cho ratios exceeded 1.0 and that started the Stupp regimen soon after maximum safe resection, the PFS durations were 26, 17, and $\geq 39$ months (Cases 7, 8, and 26, respectively). Given that total choline in MR spectroscopy reveals cell density [9], low myoinositol levels are considered associated with poor prognosis. Indeed, a recent cohort study of recurrent glioblastoma treated with bevacizumab reported that a high myoinositol value on MR spectroscopy was associated with a good prognosis [24]. Given all these results, we considered that myoinositol affects as a second messenger and has antitumor effects. Myoinositols are located in glial cells, especially in astrocytes [25], and regulate intracranial osmotic pressure [13]. Phosphatidylinositol 3-phosphate, which contains myoinositols in its structure, is produced by intracellular membrane metabolism [10] and activates the PI3K-Akt pathway as a second messenger [26]. Activation of this pathway may cause a poorer prognosis in patients with a low Ins/Cho ratio by prompting cell proliferation and myoinositol consumption. As shown in a previous study, oral administration of myoinositols can inhibit malignant transformation of tumor cells in patients suffering non-small-cell lung cancer, in which the PI3K-Akt pathway is important [27]. Other researchers also reported that myoinositols have antitumor effects that result from their phosphorylated metabolites, such as inositol 1,3,4,5,6-pentaphosphate and inositol hexaphosphate, which can induce tumor cell apoptosis $[28,29]$. These previous studies suggest that malignancy in IDH wild-type gliomas with low Ins/Cho ratios is associated with a simple reduction in antitumor effects. 
However, multivariate analysis only showed that the Ins/Cho ratio was significantly associated with PFS and not OS (Figure 1, Table 3). We assumed that the therapeutic strategies used after recurrence affected these results in the multivariate analyses. Indeed, some patients chose both surgical resection and additional chemotherapy (13\%), whereas other patients opted for no additional therapy after recurrence $(23 \%)$, potentially affecting outcomes. Notably, all patients younger than 50 years at diagnosis were in the group with a low Ins/Cho ratio, and $60 \%$ of these chose surgical resection and chemotherapy (Table 1). Two of these patients (cases 1 and 3 ) survived for approximately 2 years despite having low Ins/Cho ratios ( 0.57 and 0.51 , respectively). By contrast, $20 \%$ of patients older than 60 years at diagnosis underwent surgical resection, and only $4 \%$ of these chose additional chemotherapy. Patients who opted for no therapy after recurrence had short survival time (e.g., cases 15 and 27) despite having relatively high Ins/Cho ratios ( 0.85 and 0.69 , respectively).

Copy number analysis by next generation sequencing revealed no significant correlations between the Ins/Cho ratio and chromosomal areas, despite the association of specific copy number aberrations with glioblastoma (Table 4). Previous studies have shown that such copy number aberrations are an early stage of tumorigenesis in glioblastoma [15, 30,31], and our results suggest that low myoinositol levels are less likely to be caused by decreased myoinositol synthesis due to chromosomal change and gene expression. Rather, the low myoinositol levels can be considered to result from consumption due to tumor growth.

This study is limited by its retrospective cohort design and lack of control of therapeutic strategies (e.g., resection extent by tumor location, postoperative bevacizumab use, and radiological dosages) or postoperative complications (e.g., delayed wound healing or high-fever affected the start of adjuvant therapy). These factors could have significantly affected the clinical courses and outcomes. We must now investigate more cases to clarify the putative correlations between the Ins/Cho ratio and patient prognosis.

\section{Conclusions}

The noninvasive Ins/Cho ratio can serve as a novel prognostic marker for adults with supratentorial IDH wild-type gliomas, providing useful preoperative information in patients with suspected glioblastomas. However, we can only speculate on why myoinositols are associated with patient outcomes, and questions around this will be targeted in future research.

\section{Abbreviations}

FFPE: formalin-fixed and paraffin-embedded tissue

IDH: isocitrate dehydrogenase

Ins/Cho ratio: ratio of myoinositol to total choline 
MR: Magnetic resonance spectroscopy

OS: overall survival

PCR: polymerase chain reaction

PFS: progression free survival

VOI: voxel of interest

\section{Declarations}

Ethical approval and consent to participate: All procedures performed in studies involving human participants were in accordance with the ethical standards of the institutional research committee and with the 1964 Helsinki declaration and its later amendments or comparable ethical standards. The study was approved by the local ethical review board of Fujita Health University (HG19-017).

\section{Consent for publication}

All authors read and approved the final manuscript.

\section{Availability of data and materials}

The datasets used and/or analyzed during the current study are available from the corresponding author on reasonable request.

\section{Competing interests}

The authors declare that they have no conflict of interest.

\section{Funding}

This study was funded by a Grant-in-Aid for Young Scientists (B) from the Ministry of Education, Culture, Sports, Science and Technology in Japan (\# 16K20029 to S.N.).

\section{Authors' contributions}

MK is the author and who conducted this study. TK, HS, HK conducted the copy number analysis and drafted the manuscript. KM and $\mathrm{YO}$ analyzed metabolites of glioma in this study and drafted the manuscript. MA and SY diagnosed tissue pathologically according to the WHO classification. SN, SO, JI, $\mathrm{MH}$, and $\mathrm{YH}$ revised and edited the manuscript.

\section{Acknowledgements}

We would like to thank Ms. Fujiko Sueishi for technical support. 


\section{References}

1. Louis DN, Perry A, Reifenberger G, von Deimling A, Figarella-Branger D, Cavenee WK, Ohgaki H, Wiestler OD, Kleihues P, Ellison DW. The 2016 World Health Organization Classification of Tumors of the Central Nervous System: a summary. Acta Neuropathol. 2016, 131:803-820. https://doi.org/1007/s00401-016-1545-1.

2. Yan H, Parsons DW, Jin G, McLendon R, Rasheed BA, Yuan W, Kos I, Batinic-Haberle I, Jones S, Riggins GJ, Friedman H, Friedman A, Reardon D, Herndon J, Kinzler KW, Velculescu VE, Vogelstein B, Bigner DD. IDH1 and IDH2 mutations in gliomas. N Engl J Med. 2009, 360:765773.https://doi.org/10.1056/NEJMoa0808710.

3. Cancer Genome Atlas Research Network, Brat DJ, Verhaak RG, Aldape KD, Yung WK, Salama SR, Cooper LA, Rheinbay E, Miller CR, Vitucci M, Morozova O, Robertson AG, Noushmehr H, Laird PW, Cherniack AD, Akbani R, Huse JT, Ciriello G, Poisson LM, Barnholtz-Sloan JS, Berger MS, Brennan C, Colen RR, Colman H, Flanders AE, Giannini C, Grifford M, lavarone A, Jain R, Joseph I, Kim J, Kasaian K, Mikkelsen T, Murray BA, O'Neill BP, Pachter L, Parsons DW, Sougnez C, Sulman EP, Vandenberg SR, Van Meir EG, von Deimling A, Zhang H, Crain D, Lau K, Mallery D, Morris S, Paulauskis J, Penny R, Shelton T, Sherman M, Yena P, Black A, Bowen J, Dicostanzo K, Gastier-Foster J, Leraas KM, Lichtenberg TM, Pierson CR, Ramirez NC, Taylor C, Weaver S, Wise L, Zmuda E, Davidsen T, Demchok JA, Eley G, Ferguson ML, Hutter CM, Mills Shaw KR, Ozenberger BA, Sheth M, Sofia HJ, Tarnuzzer R, Wang Z, Yang L, Zenklusen JC, Ayala B, Baboud J, Chudamani S, Jensen MA, Liu J, Pihl T, Raman R, Wan Y, Wu Y, Ally A, Auman JT, Balasundaram M, Balu S, Baylin SB, Beroukhim R, Bootwalla MS, Bowlby R, Bristow CA, Brooks D, Butterfield Y, Carlsen R, Carter S, Chin L, Chu A, Chuah E, Cibulskis K, Clarke A, Coetzee SG, Dhalla N, Fennell T, Fisher S, Gabriel S, Getz G, Gibbs R, Guin R, Hadjipanayis A, Hayes DN, Hinoue T, Hoadley K, Holt RA, Hoyle AP, Jefferys SR, Jones S, Jones CD, Kucherlapati R, Lai PH, Lander E, Lee S, Lichtenstein L, Ma Y, Maglinte DT, Mahadeshwar HS, Marra MA, Mayo M, Meng S, Meyerson ML, Mieczkowski PA, Moore RA, Mose LE, Mungall AJ, Pantazi A, Parfenov M, Park PJ, Parker JS, Perou CM, Protopopov A, Ren X, Roach J, Sabedot TS, Schein J, Schumacher SE, Seidman JG, Seth S, Shen H, Simons JV, Sipahimalani P, Soloway MG, Song X, Sun H, Tabak B, Tam A, Tan D, Tang J, Thiessen N, Triche T Jr, Van Den Berg DJ, Veluvolu U, Waring S, Weisenberger DJ, Wilkerson MD, Wong T, Wu J, Xi L, Xu AW, Yang L, Zack TI, Zhang J, Aksoy BA, Arachchi H, Benz C, Bernard B, Carlin D, Cho J, DiCara D, Frazer S, Fuller GN, Gao J, Gehlenborg N, Haussler D, Heiman DI, lype L, Jacobsen A, Ju Z, Katzman S, Kim H, Knijnenburg T, Kreisberg RB, Lawrence MS, Lee W, Leinonen K, Lin P, Ling S, Liu W, Liu Y, Liu Y, Lu Y, Mills G, Ng S, Noble MS, Paull E, Rao A, Reynolds S, Saksena G, Sanborn Z, Sander C, Schultz N, Senbabaoglu Y, Shen R, Shmulevich I, Sinha R, Stuart J, Sumer SO, Sun Y, Tasman N, Taylor BS, Voet D, Weinhold N, Weinstein JN, Yang D, Yoshihara K, Zheng S, Zhang W, Zou L, Abel T, Sadeghi S, Cohen ML, Eschbacher J, Hattab EM, Raghunathan A, Schniederjan MJ, Aziz D, Barnett G, Barrett W, Bigner DD, Boice L, Brewer C, Calatozzolo C, Campos B, Carlotti CG Jr, Chan TA, Cuppini L, Curley E, Cuzzubbo S, Devine K, DiMeco F, Duell R, Elder JB, Fehrenbach A, Finocchiaro G, Friedman W, Fulop J, Gardner J, Hermes B, Herold-Mende C, Jungk C, Kendler A, Lehman NL, Lipp E, Liu O, Mandt R, McGraw M, Mclendon R, McPherson C, Neder L, 
Nguyen P, Noss A, Nunziata R, Ostrom QT, Palmer C, Perin A, Pollo B, Potapov A, Potapova O, Rathmell WK, Rotin D, Scarpace L, Schilero C, Senecal K, Shimmel K, Shurkhay V, Sifri S, Singh R, Sloan AE, Smolenski K, Staugaitis SM, Steele R, Thorne L, Tirapelli DP, Unterberg A, Vallurupalli M, Wang Y, Warnick R, Williams F, Wolinsky Y, Bell S, Rosenberg M, Stewart C, Huang F, Grimsby JL, Radenbaugh AJ, Zhang J. Cancer Genome Atlas Research Network, Brat DJ, Verhaak RG, Aldape KD, Yung WK, Salama SR, et al. Comprehensive, Integrative Genomic Analysis of Diffuse Lower-Grade Gliomas. N Engl J Med. 2015, 372:2481-2498. https://doi: 10.1056/NEJMoa1402121.

4. Nakae S, Sasaki H, Hayashi S, Hattori N, Kumon M, Nishiyama Y, Adachi K, Nagahisa S, Hayashi T, Inamasu J, Abe M, Hasegawa M, Hirose Y. PCR-Based Simple Subgrouping Is Validated for Classification of Gliomas and Defines Negative Prognostic Copy Number Aberrations in IDH mutant Gliomas. PLoS One. 2015, 10:e0142750. https://doi.org/10.1371/journal.pone.0142750.

5. Marko NF, Weil RJ, Schroeder JL, Lang FF, Suki D, Sawaya RE. Extent of resection of glioblastoma revisited: personalized survival modeling facilitates more accurate survival prediction and supports a maximum-safe-resection approach to surgery. J Clin Oncol. 2014, 32:774-782. https://doi.org/10.1200/JC0.2013.51.8886.

6. Oppenlander ME, Wolf AB, Snyder LA, Bina R, Wilson JR, Coons SW, Ashby LS, Brachman D, Nakaji P, Porter RW, Smith KA, Spetzler RF, Sanai N. An extent of resection threshold for recurrent glioblastoma and its risk for neurological morbidity. J Neurosurg. 2014, 120:84653.https://doi.org/10.3171/2013.12.JNS13184.

7. Stadlbauer A, Gruber S, Nimsky C, Fahlbusch R, Hammen T, Buslei R, Tomandl B, Moser E, Ganslandt $\mathrm{O}$. Preoperative grading of gliomas by using metabolite quantification with high-spatial-resolution proton MR spectroscopic imaging. Radiology. 2006, 238:958-969.

https://doi.org/10.1148/radiol.2382041896.

8. Nakae S, Murayama K, Sasaki H, Kumon M, Nishiyama Y, Ohba S, Adachi K, Nagahisa S, Hayashi T, Inamasu J, Abe M, Hasegawa M, Hirose Y. Prediction of genetic subgroups in adult supra tentorial gliomas by pre- and intraoperative parameter. J Neurooncol. 2017, 131:403-

412.https://doi.org/10.1007/s11060-016-2313-8

9. Kinoshita Y, Yokota A. Absolute concentrations of metabolites in human brain tumors using in vitro proton magnetic resonance spectroscopy. NMR Biomed. 1997, 10:2-

12.https://doi.org/10.1002/(SICI)1099-1492(199701)10:1<2::AID-NBM442>3.0.CO;2-N.

10. Abel K, Anderson RA, Shears SB. Phosphatidylinositol and inositol phosphate metabolism. J Cell Sci. 2001, 114:2207-2208.

11. Groenen PM, Merkus HM, Sweep FC, Wevers RA, Janssen FS, Steegers-Theunissen RP. Kinetics of myo-inositol loading in women of reproductive age. Ann Clin Biochem. 2003, 40:79-85. https://doi.org/10.1258/000456303321016213.

12. Dinicola S, Minini M, Unfer V, Verna R, Cucina A, Bizzarri M. Nutritional and Acquired Deficiencies in Inositol Bioavailability. Correlations with Metabolic Disorders. Int J Mol Sci. 2017, 18: 2187.https://doi.org/10.3390/ijms18102187. 
13. Cordoba J, Gottstein J, Blei AT. Glutamine, myo-inositol, and organic brain osmolytes after portocaval anastomosis in the rat: implications for ammonia-induced brain Hepatology. 1996, 24:919-923. https://doi.org/10.1002/hep.510240427.

14. Simon M, Hosen I, Gousias K, Rachakonda S, Heidenreich B, Gessi M, Schramm J, Hemminki K, Waha A, Kumar R. TERT promoter mutations: a novel independent prognostic factor in primary glioblastomas. Neuro Oncol. 2015, 17:45-52. https://doi.org/10.1093/neuonc/nou158.

15. Lopez-Gines C, Cerda-Nicolas M, Gil-Benso R, Pellin A, Lopez-Guerrero JA, Callaghan R, Benito R, Roldan P, Piquer J, Llacer J, Barbera J. Association of chromosome 7, chromosome 10 and EGFR gene amplification in glioblastoma multiforme. Clin Neuropathol. 2005, 24:209-218.

16. Feng J, Kim ST, Liu W, Kim JW, Zhang Z, Zhu Y, Berens M, Sun J, Xu J. An integrated analysis of germline and somatic, genetic and epigenetic alterations at 9p21.3 in glioblastoma. Cancer. 2012, 118:232-240. https://doi.org/10.1002/cncr.26250.

17. Meyronet D, Esteban-Mader M, Bonnet C, Joly MO, Uro-Coste E, Amiel-Benouaich A, Forest $F$, Rousselot-Denis C, Burel-Vandenbos F, Bourg V, Guyotat J, Fenouil T, Jouvet A, Honnorat J, Ducray F. Characteristics of H3 K27M-mutant gliomas in adults. Neuro Oncol. 2017, 19:11271134.https://doi.org/10.1093/neuonc/now274

18. Kuwahara K, Ohba S, Nakae S, Hattori N, Pareira ES, Yamada S, Sasaki H, Abe M, Hasegawa M, Hirose Y. Clinical, histopathological, and molecular analyses of IDH-wild-type WHO grade II-III gliomas to establish genetic predictors of poor prognosis. Brain Tumor Pathol. 2019 36:135143.https://doi.org/10.1007/s10014-019-00348-9.

19. Govindaraju V, Young K, Maudsley AA. Proton NMR chemical shifts and coupling constants for brain metabolites. NMR 2000 13:129-153. DOI: 10.1002/1099-1492(200005)13:3<129::aidnbm619>3.0.co;2-v.

20. Li Y, Lafontaine M, Chang S, Nelson SJ. Comparison between Short and Long Echo Time Magnetic Resonance Spectroscopic Imaging at 3T and 7T for Evaluating Brain Metabolites in Patients with Glioma. ACS Chem Neurosci. 2018 9:130-137. doi: 10.1021/acschemneuro.7b00286. Epub 2017 Oct 16.

21. Wilson M, Andronesi O, Barker PB, Bartha R, Bizzi A, Bolan PJ, Brindle KM, Choi IY, Cudalbu C, Dydak U, Emir UE, Gonzalez RG, Gruber S, Gruetter R, Gupta RK, Heerschap A, Henning A, Hetherington HP, Huppi PS, Hurd RE, Kantarci K, Kauppinen RA, Klomp DWJ, Kreis R, Kruiskamp MJ, Leach MO, Lin AP, Luijten PR, Marjańska M, Maudsley AA, Meyerhoff DJ, Mountford CE, Mullins PG, Murdoch JB, Nelson SJ, Noeske R, Öz G, Pan JW, Peet AC, Poptani H, Posse S, Ratai EM, Salibi N, Scheenen TWJ, Smith ICP, Soher BJ, Tkáč I, Vigneron DB, Howe FA. Magn Reson Med. Methodological consensus on clinical proton MRS of the brain: Review and recommendations. 2019 82:527-550. doi: 10.1002/mrm.27742. Epub 2019 Mar 28.

22. Provencher SW. Automatic quantitation of localized in vivo $1 \mathrm{H}$ spectra with LCModel. NMR Biomed. 2001, 14:260-264. https://doi.org/10.1002/nbm.698. 
23. Kanda Y. Investigation of the freely available easy-to-use software 'EZR' for medical statistics. Bone Marrow Transplant. 2013, 48:452-458. https://www.nature.com/articles/bmt2012244.

24. Steidl E, Pilatus U, Hattingen E, Steinbach JP, Zanella F, Ronellenfitsch MW, Bähr O. Myoinositol as a Biomarker in Recurrent Glioblastoma Treated with Bevacizumab: A 1H-Magnetic Resonance Spectroscopy Study. PLoS One. 2016, 11:e0168113. https://doi.org/10.1371/journal.pone.0168113.

25. Brand A, Richter-Landsberg C, Leibfritz D. Multinuclear NMR studies on the energy metabolism of glial and neuronal cells. Dev Neurosci. 1993, 15:289-298. https://doi.org/10.1159/000111347.

26. Maehama T, Dixon JE. The tumor suppressor, PTEN/MMAC1, dephosphorylates the lipid second messenger, phosphatidylinositol 3,4,5-trisphosphate. J Biol Chem. 1998, 273:1337513378.https://doi.org/10.1074/jbc.273.22.13375.

27. Han W, Gills JJ, Memmott RM, Lam S, Dennis PA. The chemopreventive agent myoinositol inhibits Akt and extracellular signal-regulated kinase in bronchial lesions from heavy smokers. Cancer Prev Res (Phila). 2009, 2:370-376. https://doi.org/1158/1940-6207.CAPR-08-0209.

28. Piccolo E, Vignati S, Maffucci T, Innominato PF, Riley AM, Potter BV, Pandolfi PP, Broggini M, lacobelli S, Innocenti P, Falasca M. Inositol pentakisphosphate promotes apoptosis through the PI 3K/Akt pathway. Oncogene. 2004, 23:1754-1765.https://doi.org/10.1038/sj.onc.1207296.

29. Singh RP, Agarwal C, Agarwal R. Inositol hexaphosphate inhibits growth, and induces G1 arrest and apoptotic death of prostate carcinoma DU145 cells: modulation of CDKI-CDK-cyclin and pRb-related protein-E2F complexes. Carcinogenesis. 2003, 24:555-563. https://doi.org/10.1093/carcin/24.3.555.

30. Ozawa T, Riester M, Cheng YK, Huse JT, Squatrito M, Helmy K, Charles N, Michor F, Holland EC. Most human non-GCIMP glioblastoma subtypes evolve from a common proneural-like precursor glioma. Cancer Cell. 2014, 26:288-300. https://doi.org/1016/j.ccr.2014.06.005.

31. Huse JT, Aldape KD. The evolving role of molecular markers in the diagnosis and management of diffuse glioma. Clin Cancer Res. 2014, 20:5601-5611. https://doi.org/1158/1078-0432.CCR-14-0831.

\section{Figures}


Figure la

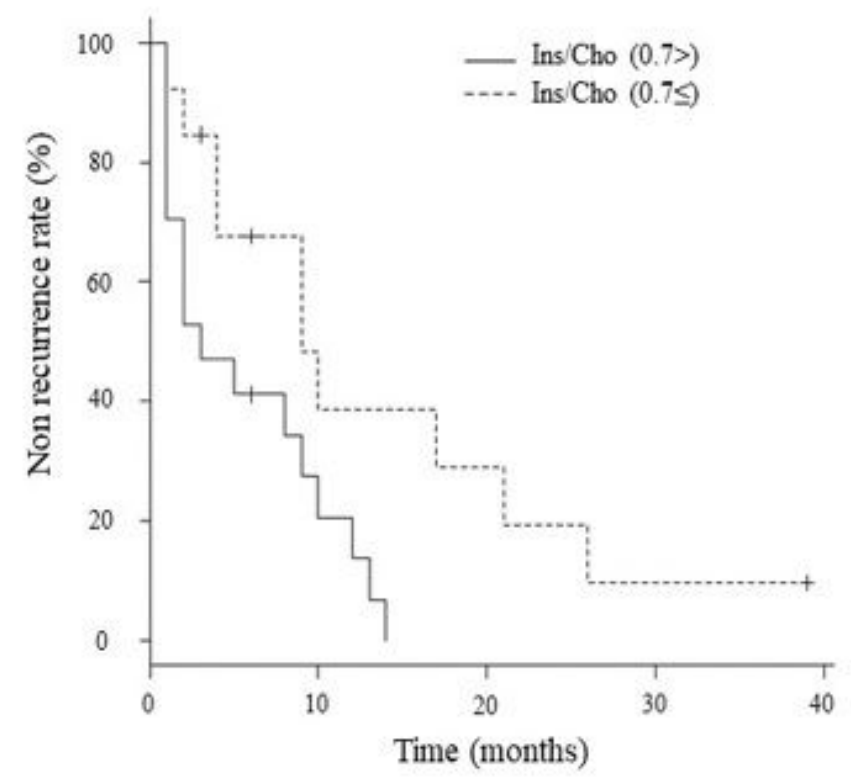

Figure 1b

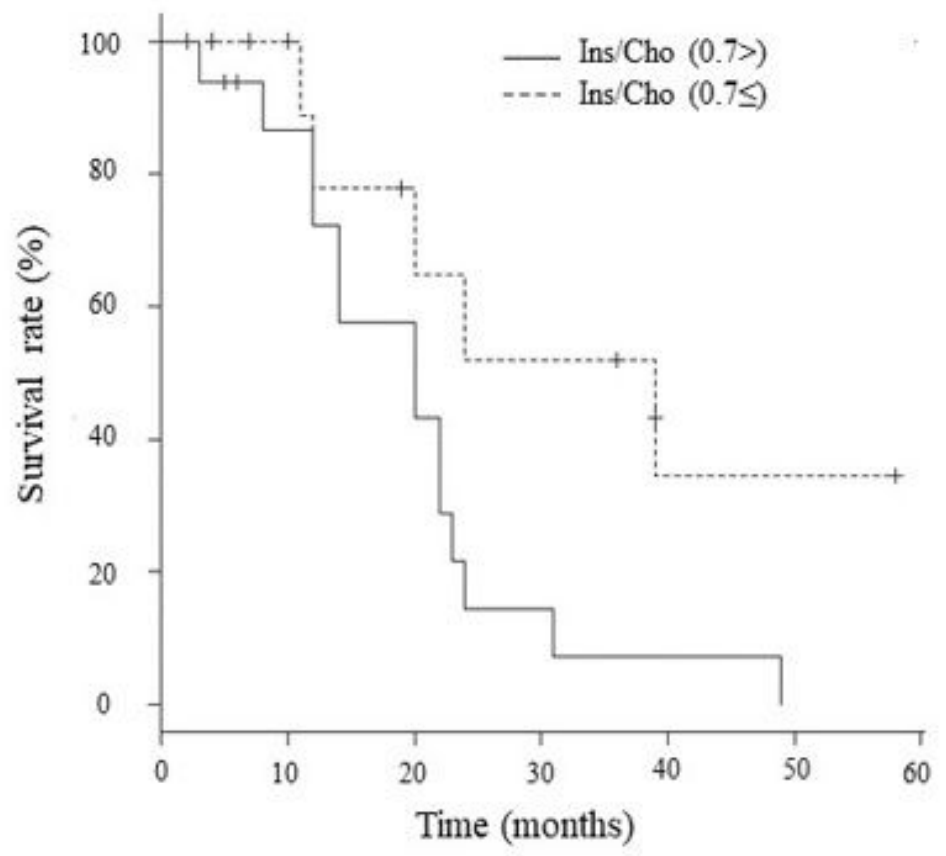

\section{Figure 1}

Comparison of PFS (a) and OS (b) between the group with a high Ins/Cho ratio $(n=13)$ and that with a low ratio $(n=17)$. Analysis was by the Kaplan-Meier method, using the log-rank test. Abbreviations: Ins/Cho, ratio of myoinositol to total Choline; OS, overall survival; PFS, progression free survival. 